\title{
A geografia dos cinemas no lazer paulistano contemporâneo: redes e territorialidades
}

\author{
dos cinemas multiplex e de arte
}

\section{The geography of cinemas in the contemporary paulistan leisure: networks and territoriality of multiplex cinemas and art}

Eduardo Baider Stefani

Mestre em Geografia Humana pela USP. Especialista em Políticas Públicas do Governo do Estado de São Paulo

Júlio César Suzuki

Doutor em Geografia Humana pela USP. Professor do Departamento de Geografia, FFLCH-USP.

\section{Resumo}

Equipamentos de lazer e cultura, as salas de cinema, que recentemente voltaram a ser social e midiaticamente discutidas por conta das manifestações populares contrárias ao fechamento do cinema Belas Artes, desempenharam fundamental papel na produção e reprodução do espaço urbano paulistano. Em anos recentes, o mercado exibidor cinematográfico paulistano foi modelado por pelo menos dois equipamentos distintos entre si: os cinemas multiplex, comumente localizado em shopping-centers, pertencentes a grandes redes empresariais, e os cinemas voltados para uma programação alternativa ou de arte, via de regra instalados em vias públicas ou em galerias, que fomentam uma apropriação do espaço que podemos alcunhar de territorialidade. Considerando tal constructo social, o objetivo primordial foi analisar o significado das salas de cinema, as ações e apropriações desenvolvidas por seus frequentadores, na e para a (re)produção do espaço urbano paulistano a partir da década de 1990, elaborando, para tanto, uma compreensão teórico-conceitual embasada nas concepções de redes geográficas e territorialidades, a partir de revisão bibliográfica, levantamentos primários e secundários e mapeamentos. A proposta epistemológica foi criar um amalgama complexo, que não mitigasse nem a relevância dos fatores culturais, causa e consequência dos cinemas, tampouco desconsiderasse a estruturação e as motivações econômicas dos agentes que coordenam a organização destes equipamentos. Crê-se, nesse sentido, que o trabalho subsidiou uma crítica densificada de fenômenos e processos culturais e econômicos responsáveis, em alguma medida, pela produção do espaço urbano contemporâneo e seus significados sociais.

Palavras-chave: Cinema; Redes; Lazer; Territorialidades; São Paulo.

\section{Abstract}

Leisure facilities and culture, cinema, who recently returned to be social and mediatically discussed on account of public protests opposing to the closure of the Fine Arts Cinema, played as a key role in the production and reproduction of urban space in São Paulo. In recent years, the film exhibition market in São Paulo has been modeled by at least two different units together: the multiplex cinemas, often located in shopping centers, owned by large corporate networks, and cinemas that are movie-oriented alternative programming, installed in public streets or in galleries, which foster an appropriation of space we can nickname as territoriality. Given this social construct, the primary objective was to analyze the meaning of cinema facilities, the actions and appropriations developed by its visitors, in and for the (re) 
production of the urban space in the capital of Sao Paulo state starting from the 1990's, elaborating for this a theoretical and conceptual understanding based on the concepts of territoriality and geographical networks, from a literature review, with a primary and secondary surveys and mappings. The epistemological aim was to create an amalgam complex that does not mitigate nor the relevance of cultural factors, causes and consequences of the cinemas, nor disregarding the structure and the economic motivations of agents that coordinate the organization of such equipment and facilities. It is believed, in this sense, that the work subsidized a densified critical of phenomena and cultural and economic processes, responsible, in some extent, by the production of contemporary urban space and its social meanings.

Key-words: Cinema; Networks; Leisure; Territoriality; São Paulo.

\section{Introdução}

O sentido da análise que percorremos é o da construção de uma Geografia das Salas de Cinema do município de São Paulo.

Pode-se dizer que São Paulo "respira" cinema. Como ressalta André Sturm, um dos principais distribuidores de cinema no município de São Paulo, em entrevista concedida a Almeida (2000, p.178), São Paulo oferece, hoje, um circuito de cinema que, em quantidade e qualidade, só pode ser comparado a Nova York e Paris. Para ele, se compararmos a programação de cinema de Londres e São Paulo "em um dia só, com raríssimas exceções, São Paulo (...) ganha longe na diversidade e na quantidade de filmes".

As salas de cinema constituem um dos mais distribuídos equipamentos de lazer existentes na atualidade paulistana. A atuação deste elemento para a produção e para a reprodução do espaço urbano, tal como amplamente conceituado por autores como Carlos (2004), é decisiva, uma vez que direciona a construção de conjuntos de substratos que possuem significados e ambiências diferenciadas, realizando (ou não) a interação com o espaço urbano, articulando o fluxo de pessoas e serviços relacionados, bem como influenciando o comportamento de contingentes de indivíduos com interesses e perfis sociais afins.

Debruçando-se sobre esse panorama complexo, a pesquisa tomou como referência o cinema enquanto equipamento de lazer ${ }^{1}$, composto, no cenário paulistano, por dois elementos com características deveras diferenciadas entre si, numa tipologia destacada por Santoro

\footnotetext{
${ }^{1}$ Como equipamento de lazer, compreendemos, com base em Santini (1993, p.47), “o conjunto de instalações que servem de apoio para atividades de lazer". Trata-se, pois, do substrato físico, inserido no espaço, que propicia condições materiais para a realização de atividades de lazer, públicas ou privadas, culturais ou esportivas, associativas ou individuais. Com efeito, cada cinema constitui um equipamento de lazer.
} 
(2004) e Simões (1990): os multiplex, localizados preponderantemente em shopping-centers, e os cinemas de arte, estabelecidos, em geral, em via pública ou em galerias.

O primeiro elemento, constituído pelos cinemas multiplex, mostra-se quase onipresente no espaço paulistano, correspondendo a 50.461 poltronas no município de São Paulo, ou quase $85 \%$ do total disponível ${ }^{2}$. A despeito da expressão numérica, os multiplex possuem uma disposição quase sempre recorrente: trata-se de um complexo de salas de tamanho pequeno ou médio, um largo corredor de acesso comum, uma bonbonnière, uma estrutura padronizada de organização das salas, uma concorrência pelo usufruto da melhor tecnologia disponível no mercado no que se refere à projeção, que atenda a todos os requisitos exigidos pelo consumidor moderno, como salienta Oliveira (2003).

Os cinemas do tipo multiplex localizam-se em ambientes fechados, em especial shopping-centers, apresentando várias salas com uma programação baseada em filmes tradicionais, cuja linguagem já é dominada pelo público consumidor, em geral hollywoodianos e, mais recentemente, filmes populares nacionais, e pertencendo a algumas grandes redes de exibição, tais como a Cinemark, a Play-Arte e a UCI. Tais redes constituíram, a despeito do pouco tempo operando no município de São Paulo (sobretudo a partir da década de 1990), uma atuação decisiva para a produção e reprodução do espaço urbano, ao se expandir - de forma anexa aos shopping-centers - às regiões centrais e às periferias da capital paulista, incorporando o rótulo de equipamentos de lazer e sujeitando o entretenimento usual de muitos dos cidadãos paulistanos.

Compreende-se que o segundo elemento, as salas de arte, correspondente a 6.021 poltronas, ou $11 \%$ do total ${ }^{3}$, e, portanto, bastante inferior quantitativamente ao primeiro, merece ser estudado principalmente ao se considerar sua relevância na e para a fomentação de práticas sociais apropriativas que, quando transpostas no espaço, engendram territorialidades estáveis e repletas de significados. Os cinemas de arte, ao contrário dos multiplex, não possuem uma disposição física padrão, podendo possuir um número irregular de salas. Seu principal fator homogeneizador consiste, essencialmente, no oferecimento de uma programação alternativa, com filmes europeus, asiáticos e independentes. Destaca-se, $a$ priori, que existe uma territorialidade específica de cinemas de arte no município paulistano, localizada na área da Avenida Paulista. Nesta área, com extensão de cerca de 4 km, constituise aquele que é o mais importante núcleo de concentração de cinemas de arte da América Latina, composto, na atualidade, por 7 cinemas com 29 salas de exibição e 5.290 poltronas.

\footnotetext{
${ }^{2}$ Em Dezembro de 2009.

${ }^{3}$ Em dezembro de 2009.

Geo UERJ - Ano 13, nº. 22, v. 2, $2^{\circ}$ semestre de 2011 p. 379-394 - ISSN 1981-9021 http://www.e-publicacoes.uerj.br/index.php/geouerj
} 
Considerando tal constructo espaço-social, o objetivo primordial foi analisar o significado das salas de cinema, as ações e apropriações desenvolvidas por seus frequentadores, na e para a (re)produção do espaço urbano paulistano a partir da década de 1990, elaborando, para tanto, uma compreensão teórico-conceitual embasada nas concepções de redes geográficas e nas territorialidades decorrentes de apropriações espaciais. Não foi em vão a escolha das categorias rede e territorialidade para a análise do objeto de pesquisa: tratase, certamente, de dois conceitos-chave de uma Geografia que se propõe atenta à produção e à reprodução espaciais de nossa época, sendo fundamentais para a compreensão do espaço paulistano. Ao se analisar as redes e as territorialidades que as salas de cinemas e a ação de seus frequentadores no município de São Paulo evocam, buscou-se elaborar uma pesquisa temática que permitisse compreender a evolução do objeto de pesquisa, isto é, as redes e as territorialidades dos cinemas multiplex e de arte.

No que se refere ao primeiro elemento, redes, pode-se afirmar, por exemplo, que é por meio de seu estudo que se pode compreender os motivos que levaram (e continuam a levar) à expansão dos cinemas multiplex em direção à periferia paulistana, dentro dos shoppingcenters localizados nestas áreas. Embasados por Castells (1999), afirmamos que a lógica de atuação das empresas em rede, ou sua organização em formato de empresas-rede, especialmente no âmbito da exibição cinematográfica, está intrincada em processos contemporâneos de reprodução ampliada do capital, gerados no bojo da mass media.

Já no que tange à importância do segundo elemento, territorialidades, pode-se afirmar que permitiu compreender a apropriação espacial que os frequentadores fazem dos cinemas. Bastante em voga na geografia brasileira contemporânea e categorizada por autores como Costa $(2004,1999)$, o que se chamou por territorialidade no estudo é o resultado de diferentes formas de apropriação (por meio de poder político, econômico, cultural, linguístico, étnico, entre outros) de uma localidade ou região, que é constituída por meio de relações interpessoais (a sociedade) com o substrato físico (o espaço).

Desta forma, tendo como referência a possibilidade da interpretação analítica e crítica do espaço como resultante de múltiplas determinações (históricas, econômicas, sociais e culturais), a escolha metodológica do estudo só pôde decorrer de uma problematização teórica que envolveu o levantamento de fontes e documentos a partir de diferentes óticas na busca da compreensão dos fatores responsáveis pela produção da realidade estudada. Numa imbricada relação entre produção e apropriação do espaço, acreditamos que se encontra o leitmotiv do estudo. Isto porque, em nossa concepção, não é possível compreender as salas de cinema ignorando, por um lado, as relações econômicas produtivas (e reprodutivas) que os precedem 
e, por outro, desmerecendo sua importância na construção de simbolismos e apropriações subjetivas por seus frequentadores.

\section{Primórdios das salas de cinema na cidade de São Paulo: triângulo histórico e Cinelândia}

É possível compreender que uma análise da evolução dos cinemas na urbanidade paulistana pode auxiliar na compreensão das dinâmicas espaciais, em momentos distintos, da própria cidade de São Paulo. Os livros de Galvão (1975) e Araújo (1981), cada qual a sua maneira, com o seu recorte espaço-temporal, são indispensáveis para a compreensão do cinema na cidade de São Paulo desde a sua inserção, numa sala improvisada na Rua São Bento, em 1907.

Galvão (1975), por exemplo, discute a implantação e o início dos cinemas no município, apontando sua articulação com a urbanização que se realizava, com o fluxo de imigrantes que se intensificava e com a própria idéia de modernidade, a partir, inclusive, de inúmeros relatos de personagens que frequentaram, projetaram ou direcionaram os rumos do cinema desta época. Em idos das décadas de 1920, 1930 e meados da década de 1940, como relata o autor, as salas de cinema se concentram no centro tradicional, na área do Triângulo Histórico (Ruas São Bento, Direita e Barão de Itapetininga), colaborando para a construção simbólica daquela que foi a primeira centralidade econômica, funcional, cultural e de lazer do município de São Paulo. Numa relação retro-alimentada, os primeiros cinemas, via de regra instalados em salões improvisados, acabavam por constituir, conjuntamente com os circos e os teatros, o diminuto leque de opções de lazer e cultura numa cidade de São Paulo em seus anos iniciais de crescimento econômico, demográfico e espacial, atraindo indivíduos ao centro, e estando sediados lá pela existência de um fluxo regular e considerável de pessoas.

A existência de salas de cinema na área do Triângulo Histórico deu lugar, paulatinamente, a um constructo bem maior e bem mais relevante a ser produzido, espacial e socialmente, em anos posteriores, ainda no centro tradicional de São Paulo. Araújo (1981) finaliza seu estudo com uma análise do apogeu e da crise da territorialidade que ficou conhecida como a Cinelândia paulistana, isto é, a histórica (e, evidentemente, geográfica) concentração das grandes salas de cinema na área central da cidade de São Paulo. A concentração de grandes e rebuscadas salas de cinemas no centro tradicional, iniciada na década de 1940, maximizada na década de 1950, cujo declínio ocorreu a partir da década de 1960, numa área migrada do Triângulo Histórico para os corredores das Avenidas Ipiranga e 
São João, é considerada pelo autor, e consensualmente pela literatura afim, como o maior locus destes equipamentos já existente no município de São Paulo.

A Cinelândia representou, simbólica e concretamente, o apogeu dos cinemas enquanto equipamentos de lazer, na medida em que congregou as maiores salas já construídas com essa finalidade no município de São Paulo, com a atração do maior público registrado durante toda sua história, realizando-se, ainda, numa época que a visita aos cinemas estava profundamente imbuída de status social ${ }^{4}$. Não obstante, a Cinelândia ainda representou, tal qual um ícone, o apogeu do próprio centro tradicional do município de São Paulo, em qualificação funcional e social, num momento anterior à sua decadência e à migração de atividades e equipamentos para outras centralidades mais valorizadas. Simões (1990), que realizou um belíssimo estudo fotográfico (mas não apenas visual) das salas de cinema de São Paulo, dedicou especial importância à análise da crise do setor de exibição cinematográfica, desencadeada a partir da década de 1960, cujo auge ocorreu na década de 1970. Colocar em foco essa crise estrutural dos cinemas do município de São Paulo é parelho a afirmar a decadência da Cinelândia e do próprio centro tradicional paulistano.

Se, num primeiro momento, especificamente na década de 1960, o fechamento de salas se dá especificamente na Cinelândia, como efeito demonstrativo da desvalorização funcional do centro tradicional, num segundo passo, o fenômeno de fechamento de salas já se alastra por outras áreas do município paulistano, especialmente em bairros de origem operária. Outrossim, as causas do fenômeno expressivo do fechamento de cinemas, nessas duas décadas, estão relacionadas para além da dinâmica espacial paulistana. É nessa época, pois, que a televisão se potencializa enquanto principal fonte de entretenimento na sociedade brasileira urbana, incorporando grande parte do público que, anteriormente, se via obrigado a frequentar cinemas para travar contato com imagens animadas.

\section{A transição do modelo: a expansão dos cinemas fora do centro tradicional}

A partir da década de 1960, mas principalmente durante a década posterior, a abertura de cinemas começa a se dar predominante em bairros valorizados do centro expandido, especialmente nas zonas oeste e sul. Se, num primeiro momento, parte dos cinemas, anteriormente localizados no centro tradicional, passam a migrar numa expansão à Avenida

\footnotetext{
${ }^{4}$ A Cinelândia paulistana marca, espacial e socialmente, um momento singular do cinema enquanto lazer. Nessa época, ir ao cinema constituía, segundo Simões (1990), um acontecimento social; nas palavras de Graeme Turner (1997), ir ao cinema, naquela época, estava imbricado em algo que ele chama de status ritual. Estar nos cinemas da Cinelândia em seu apogeu, ver e ser visto por lá, era a atividade social de lazer mais valorizada socialmente.
} 
Paulista por meio da Rua Augusta, em seguida as salas seguem num contínuo parelho às das grandes vias de circulação e aos shopping-centers.

A dissertação de mestrado de Santoro (2004) sintetiza e atualiza a discussão ora exposta, aportando suas constatações no início dos anos 1990, chegando a identificar o fenômeno dos cinemas em shopping-centers. Ao longo da década de 1990, o panorama desenhado potencializaria-se, consolidando a bipolarização da exibição nos cinemas multiplex e os cinemas de arte. O mapa 1, de autoria de Santoro (2004), ilustra excepcionalmente bem o panorama que teve início na década de 1980, acentuado no decorrer da década de 1990, e que, acreditamos, permite-nos falar na dicotomia atual entre cinemas de arte e multiplex de shoppings-centers. Ainda que seja possível observar uma quantidade expressiva de cinemas na área central tradicional da cidade de São Paulo, na antiga Cinelândia, não se pode esquecer que, com exceção do Marabá, todos os outros exibem apenas filmes eróticos, constituindo, portanto, um público e uma programação muito especiais, os quais o escopo da pesquisa não objetivava abarcar.

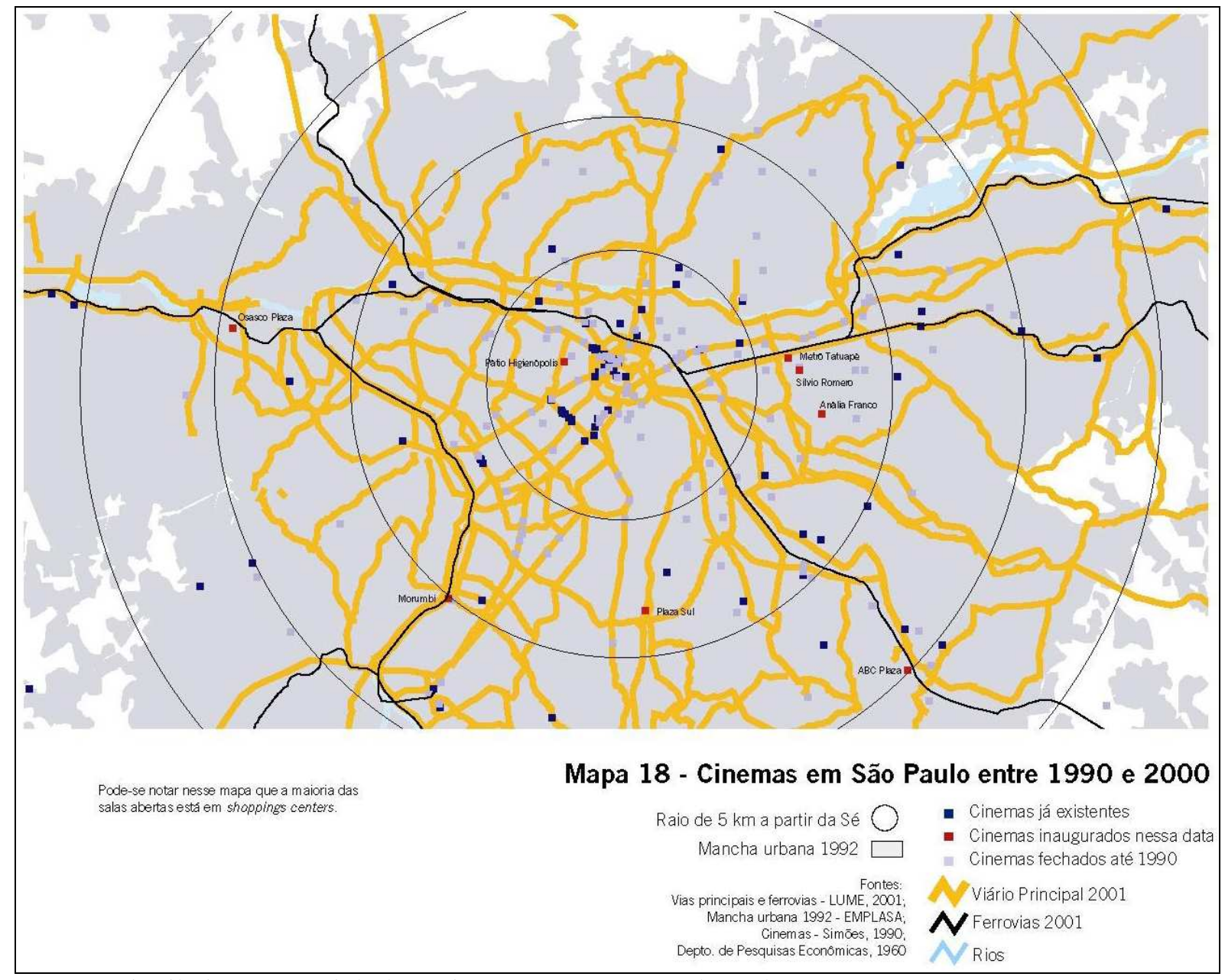

Mapa 1 Distribuição espacial dos Cinemas na área nuclear da RMSP entre 1990 e 2000. Fonte: SANTORO (2004) 
Como se pode perceber, as inaugurações de novas salas de cinema nas décadas de 1980 e 1990 foram subsidiadas, de um lado, pela inauguração de shopping-centers (Eldorado, Morumbi, Lar Center, Center Norte e Cal Center ${ }^{5}$ ), e de outro lado, pelo aquecimento do mercado representado pelos cinemas de arte (Gaumont Belas-Artes e Cinearte, ambos localizados na Avenida Paulista). Importante é notar o grande número de fechamentos de cinemas, especialmente na área central da cidade, marcando, de maneira inconteste, o arrefecimento da outrora Cinelândia, bem como do centro tradicional enquanto local imbuído de status para a realização de atividades de lazer socialmente valorizadas.

\section{A consolidação do panorama contemporâneo: cinemas multiplex em shoppings e cinemas de rua}

Na década de 1990, o panorama delineado nos anos anteriores é definitivamente consolidado. Todas as aberturas de novos cinemas ocorrem em shopping-centers (no município de São Paulo: Morumbi 2, Metrô Tatuapé, Silvio Romero, Anália Franco, Pátio Higienópolis, Plaza Sul). A área da Avenida Paulista se reafirma como pólo de exibição de filmes alternativos. O cenário espaço-social basal da dualidade multiplex e cinemas de arte é constituído. Este panorama bipolar, que até o momento pode parecer não passar de uma divisão arbitrária, é corroborado quando analisamos os dados atuais da divisão de cinemas e poltronas na capital paulista. Em setembro de 2009, a cidade de São Paulo possuía (desconsiderando as salas eróticas) 67.392 poltronas disponíveis em cinemas multiplex, de arte regulares, cineclubes e salas especiais de exibição e de bairro. Os cinemas de bairro congregavam 590 poltronas, isto é, $1 \%$ do total. Os cinemas de arte regulares somavam 6.201 poltronas, enquanto que os cineclubes e salas especiais de exibição somavam 1.942 lugares. Os restantes 50.461 lugares estavam presentes em multiplex, dos quais apenas o Bristol (galeria na esquina da Rua Augusta com a Paulista), o Kinoplex Itaim (esquina da Rua Joaquim Floriano com a Rua Bandeira Paulista) e o Marabá (Avenida Ipiranga, no centro tradicional) estão fora de shopping-centers. A tabela 1 e o gráfico 1, bem como o mapa 2 , ilustram este panorama.

\footnotetext{
${ }^{5}$ Também localizado na Paulista, em Galeria comercial, mas voltado a uma programação comercial. Geo UERJ - Ano 13, nº. 22, v. 2, $2^{\circ}$ semestre de 2011 p. 379-394 - ISSN 1981-9021 http://www.e-publicacoes.uerj.br/index.php/geouerj
} 
Tabela 1 Distribuição das Poltronas em Cinemas no município de São Paulo em setembro de 2009

\begin{tabular}{|l|l|l|l|l|}
\hline $\begin{array}{l}\text { Tipos de } \\
\text { Cinema }\end{array}$ & multiplex & $\begin{array}{l}\text { Cinemas de } \\
\text { Arte-regulares }\end{array}$ & $\begin{array}{l}\text { Cineclubes e } \\
\text { espaços } \\
\text { especiais de } \\
\text { exibição }\end{array}$ & $\begin{array}{l}\text { Cinemas de } \\
\text { bairro }\end{array}$ \\
\hline Poltronas & 50.461 & 6.201 & 1.942 & 590 \\
\hline Total: 67.392 & & & & \\
\hline \hline
\end{tabular}

Fonte: Guia Semanal do Jornal O Estado de São Paulo e Guia do Jornal A Folha de São Paulo, correspondentes ao período de 11/09 a 17/09/2009.

Organização: STEFANI, Eduardo Baider.

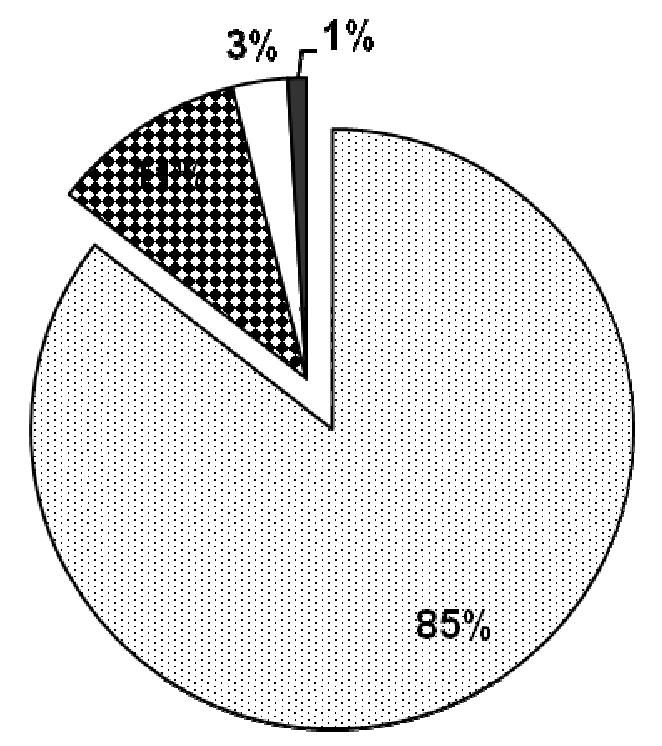

Multiplex's

Cinemas de arte-regulares

$\square$ Cineclubes e espaços especiais de exibição

口Cinemas de bairro

Gráfico 1 Distribuição das Poltronas em Cinemas no município de São Paulo em setembro de 2009. Fonte: Guia Semanal do Jornal $O$ Estado de São Paulo e Guia do Jornal $A$ Folha de São Paulo, correspondentes ao período de 11/09 a 17/09/2009.

Organização: STEFANI, Eduardo Baider

Os elementos gráficos apresentados nos permitem tecer alguns comentários preliminares acerca da organização do mercado exibidor de cinema no município de São Paulo em 2009. Nota-se, pois, tanto a prevalência de fenômenos espaço-sociais que potencializam processos cujas origens se encontram em décadas pretéritas, quanto novos fatos sociais, que estabelecem novas configurações para e do espaço urbano. Um dos fatores mais salientes é a concentração de cinemas em shopping-centers, novos ou antigos, espalhados heterogeneamente pelo espaço paulistano. Fenômeno que se constituía enquanto tendência a 
partir dos anos 1970, hoje se mostra o paradigma dominante, ao menos quantitativamente, compreendendo mais de $80 \%$ das poltronas de salas disponíveis.

Se correlacionarmos a disposição dos cinemas com a área edificada paulistana, percebe-se que, num contínuo que tem suas origens desde pelo menos 1970, as unidades se concentram especialmente em duas regiões da cidade: sul e oeste. Nestas áreas, a construção ou a manutenção dos cinemas não se dão aleatoriamente; ocorre ou nos bairros mais valorizados economicamente, local de residência de grupos de indivíduos mais abastados e, assim, consumidores com maior potencial de compra, ou conectado às vias de trânsito rápido, grandes avenidas que funcionam como importantes eixos de ligação da metrópole. 


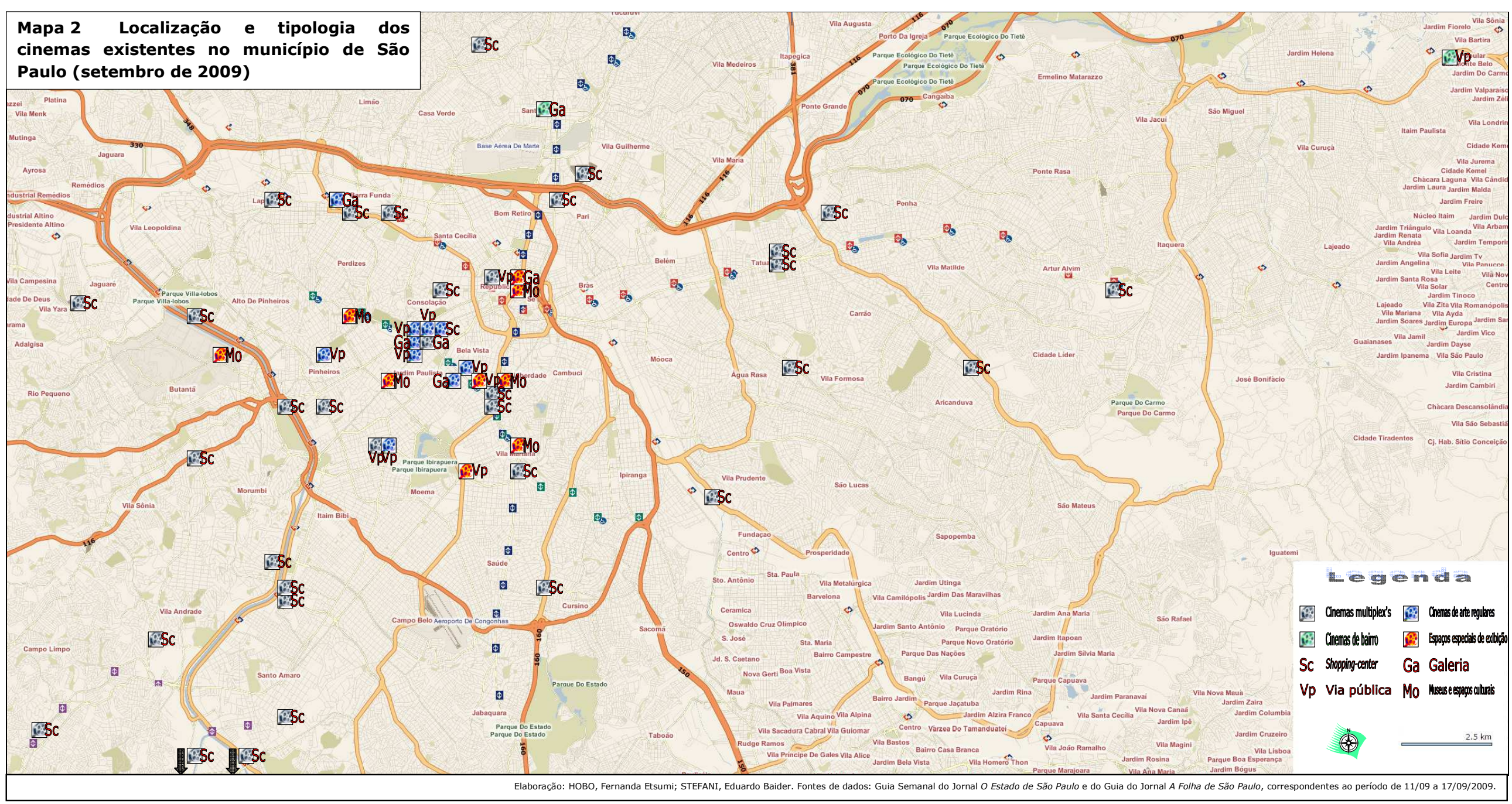

Geo UERJ - Ano 13, nº. 22, v. 2, 2º semestre de 2011 p. 379-394 - ISSN 1981-9021 http://www.e-publicacoes.uerj.br/index.php/geouerj 
$\mathrm{Na}$ região sul, em específico, percebe-se a instalação de cinemas em shoppingcenters em áreas bastante afastadas do centro tradicional da capital, como resultado de uma ocupação recente e valorizada desses espaços, adjacente ao avanço da metrópole na direção que ficou conhecida como vetor sudoeste. A presença cada vez mais intensa de cinemas na região oeste, formando uma rede cada vez mais interligada de nós, é decorrência direta dos processos de valorização econômica, funcional, mesmo simbólica, deste espaço, em especial naqueles bairros mais próximos do centro expandido.

Não obstante tais constatações, outra região da capital apresenta um novo cenário do mercado de exibição associado aos shopping-centers. A região leste é a área da capital que possui a maior quantidade de shopping-centers e, desta forma, de cinemas, anexos a estações de Metrô, num total de 3. Nesse caso, o elemento atrativo de indivíduos continua a ser, preponderantemente, o transporte, mas de outra origem, pública, diferentemente do que ocorre nos shoppings distantes de estações de Metrô ou da CPTM; esse fator pode ser creditado à grande dependência dos indivíduos moradores desta macro-área dos modais do transporte público.

Dois elementos plotados nos instrumentos gráficos, já que fazem parte do cenário exibidor cinematográfico paulistano, mas que não constituíram alvo de críticas mais densas no decorrer da pesquisa, também proporcionam algumas constatações interessantes. Os dois cinemas típicos de bairros existentes do município de São Paulo são, como já foi dito, reminiscências de um grupo que outrora era deveras rico em quantidade. Analisando-se as conclusões de Santoro (2004), isto é, debruçando-se sobre a evolução dos cinemas no município de São Paulo de 1950 a 2000, fica claro que, concomitante ao auge da Cinelândia, nas décadas de 1950 e 60, era expressiva, no espaço paulistano, a existência de um conjunto saliente de cinemas de bairro, localizados em distritos de residências operárias, formando um grupo composto por grandes salas de programação popular, sem o status dos cinemas centrais.

A partir da década de 1970, no entanto, tem início um processo de constante declínio de salas de rua ou em galerias afastadas do centro expandido, em decorrência de razões como a relação viciosa de aumento dos preços dos ingressos e diminuição do poder de compra da classe média-baixa, bem como da introdução maciça da televisão no cotidiano do indivíduo urbano. Pode-se afirmar que não apenas o apogeu da Cinelândia é temporalmente parelho ao apogeu dos cinemas de bairro, mas que também o declínio do primeiro elemento se deu de maneira comparável ao do segundo. Durante a década de 1990, no momento em que a Cinelândia se tornava praticamente inexistente, o mesmo quase se dava com os tradicionais 
cinemas de bairro, suplantados, em parte, pelos cinemas distantes do centro expandido, mas localizados em novos shopping-centers. Dos dois exemplares dos cinemas de bairro, um é bastante especial. O Itaim Paulista é o equipamento de cinema cuja localização é a mais extremada, em relação ao centro tradicional, em todo o município de São Paulo, desempenhando, em seu bairro, uma função muito pouca ofertada: de lazer e entretenimento.

O outro elemento, composto por cineclubes e espaços especiais de exibição, também encontra nos instrumentos gráficos algumas explicações. Sua notória concentração no centro expandido, especialmente em bairros valorizados das zonas sul e oeste, é mostra de que seu público regular também vive, trabalha ou passeia nestas áreas; é resultado, ainda, de uma constatação mais sutil: funções de alto valor social agregado e imbuídas de status, tais como as culturais, tendem a acompanhar espacialmente, como causa ou consequência, a valorização econômica do espaço urbano. Considerando tal apontamento, constitui fator interessante perceber que, cada vez mais, são encontrados equipamentos culturais no centro tradicional, atuantes como importantes agentes num projeto intencional que visa a requalificação funcional e simbólica dessa área. Alguns destes equipamentos possuem, entre o leque de suas atividades culturais, salas de cinema que, adequadas à tipologia já anteriormente definida, exibem mostras e retrospectivas especiais. O cinema Marabá, recém-reinaugurado, pode ser considerado como um insumo privado desse anseio, capitaneado por algumas organizações da sociedade civil e por determinadas políticas públicas governamentais ${ }^{6}$.

Visando os elementos gráficos, identifica-se um espaço específico, que sedia o maior locus de cinemas da capital: a área ampliada da Avenida Paulista. A origem desse espaço enquanto território de equipamentos de lazer e cultura, como vimos, tem sua origem histórica na desvalorização econômica e simbólica do centro tradicional e da consequente migração de muitas de suas funções de alto valor agregado para a área da Paulista, alçando-a, espacialmente, por meio de um transbordamento nuclearizado, num primeiro momento, pela Rua Augusta. Em 2009, a área da Avenida Paulista concentrava 7 cinemas de arte, 2 espaços especiais de exibição e, ainda, 3 cinemas multiplex. Constituía, assim, um cenário que, em alguma medida, pode ser comparado à outrora Cinelândia e ao próprio centro tradicional, se colocarmos em foco a imanência simbólica que subsidia uma identificação com o espaço da cidade. A área da Avenida Paulista e a apropriação que determinados grupos de indivíduos fazem de seu espaço, tendo como elo conector o cinema de arte, engendram uma territorialidade específica nesta área, como descreveu Stefani (2007).

\footnotetext{
${ }^{6}$ Tal como a ONG Viva o Centro e o projeto da Prefeitura do Município de São Paulo Nova Luz. Geo UERJ - Ano 13, nº. 22, v. 2, $2^{\circ}$ semestre de 2011 p. 379-394 - ISSN 1981-9021 http://www.e-publicacoes.uerj.br/index.php/geouerj
} 


\section{Considerações finais}

A pesquisa proporcionou subsídios que permitiram responder as problemáticas específicas referentes à produção e à reprodução do espaço urbano a partir da organização do equipamento de lazer cinema, composto por dois elementos principais, os cinemas multiplex $\mathrm{e}$ os cinemas de arte, que constituem territorialidades e estão dispostos em rede. O método utilizado valeu-se da depuração de quais condições, de que maneira, com quais consequências as territorialidades e as redes acontecem para os multiplex e os cinemas de arte no município de São Paulo.

Nenhuma outra cidade do país possui a oferta de exibição simultânea de filmes que São Paulo oferece. A grande população, o contingente social abastado, a presença das sedes das grandes produtoras e distribuidoras são fatores que contribuem para a consolidação deste fato. A cidade é sinônima de cinema no Brasil, sendo este é um fato reconhecível e notório. Os cinemas de São Paulo são muitos. Maiores em quantidade do que em diversidade. Há, no panorama do lazer cinema no espaço paulistano, uma bipolaridade de características e públicos, numa contraposição evidente entre programações e anseios sobre um filme, representada por dois tipos de equipamentos: os multiplex e os cinemas de arte.

As redes de exibição, multinacionais ou de capital ainda nacional, que formataram o mercado no padrão de multiplex, apresentam-se numa tendência contínua de concentração e maximização de unidades. Se analisado o mercado exibidor paulistano na última década, veremos que, ano após ano, enquanto o número de salas, em absoluto, aumentava, o número de exibidores diminuía; em 2009, apenas uma única rede, a Cinemark, administrava mais de $50 \%$ das poltronas disponíveis em salas de cinema de São Paulo. O fenômeno de concentração das unidades de serviços, os cinemas, em algumas poucas redes, é causa e consequência da estruturação econômica empresarial de nossos dias; ilustra, pois, um momento de concentração do capital para potencialização das condições de competitividade, caminhando concomitantemente com uma prospecção localizacional cada vez mais relevante para instalação dos nós responsáveis por reproduzir o capital.

A estruturação das empresas de exibição de cinema em formato de rede não significa, em nenhum sentido, uma descentralização do capital, na medida em que há um comando central cada vez mais evidente; tampouco evidencia uma espécie de incorporação de pequenas empresas no mercado, que abarca cada vez menos agentes. A empresa em rede no ramo do lazer e entretenimento, tal como foi analisado no decorrer da pesquisa, tende a uma 
concentração espacial em que há possibilidades de redução do tempo de giro do capital, por já haver um mercado consumidor consolidado. Tende, pois, a criar suas unidades ou nós no espaço urbano das grandes cidades ou metrópoles, procurando, nestas áreas, os espaços subaproveitados, ou seja, que possuem mercado potencial consumidor ainda pouco contemplado.

Dado a pujança dos multiplex em shopping-centers, o surpreendente é constatar que no município também há um outro mercado relevante, constituído por cinemas e filmes alternativos. Estes cinemas e suas programações, a despeito da participação diminuta no circuito, fomentam, em grande parte, a condição de núcleo cinematográfico que a cidade emana. É este circuito, por exemplo, que sedia a maior e mais importante mostra de cinema da América Latina, a Mostra Internacional de Cinema de São Paulo. Fomentam, pois, uma variedade de exibição que só pode ser comparada a cidades como Nova York e Paris.

Este circuito alternativo, composto por cinemas de arte de programação regular, tendeu a se estabelecer historicamente em determinados locais. A partir da década de 1960, mas principalmente após a década de 1980, os cinemas com programação de arte tenderam a se instalar na área da Avenida Paulista. Ocorre que, desde a década de 1960, a Paulista já dispunha de vários cinemas, constituindo-se como um pólo de exibição na cidade. Trata-se, pois, de uma territorialidade que possui duas facetas, a objetiva e a subjetiva, que se retrodeterminam numa interação dialética.

A análise dos cinemas multiplex e de arte nos coloca diante de algumas importantes considerações, especialmente sobre as (im)possibilidades do consumo e seus impactos para a apropriação do espaço. O debate acerca das salas de cinema no espaço urbano paulistano permitiu a compreensão de que sua realização não se encerra em si mesmo; diferentes consumos de diferentes filmes engendram formas diversas de apropriação do espaço pelos indivíduos, constituindo territorialidades mais ou menos densas. O território se define em evidência do lugar para cada um de nós e, por isso mesmo, ultrapassa a condição de agente passivo ao qual nos mantemos inertes. Nós condicionamos e interpretamos o território, subjetivando-o. Em momentos específicos de nossas vidas, nós nos apegamos a determinados locais, desenvolvendo afeição a partir de ações compartilhadas com outros indivíduos. Assim, perceber que, mesmo num mundo fugaz, nós participamos, inadvertidamente ou não, de territorialidades subjetivas e objetivas, é perceber também a importância fundamental do lugar, enquanto espaço de possibilidade para a realização das nossas interações sociais, sociabilidades, lazeres, quer intermediados pelo consumo, quer não. Tornamos nossos alguns lugares das cidades, sejam eles quais forem. 


\section{Referências}

ALMEIDA, Heloísa Buarque de. Janela para o mundo: representações do público sobre o circuito de cinema de São Paulo. (In): MAGNANI, José Guilherme C. Na metrópole: textos de antropologia urbana. São Paulo: Edusp/Fapesp, 2000.

ARAÚJO, Vicente de Paula. Salões, Circos e Cinemas de São Paulo. São Paulo: Perspectiva, 1981.

CARLOS, Ana Fani Alessandro. O espaço urbano: novos escritos sobre a cidade. São Paulo: Contexto, 2004.

CASTELLS, Manuel. A sociedade em rede. $10^{\circ}$ ed. Rio de Janeiro: Paz e Terra, 1999.

COSTA, Rogério Haesbaert da. O mito da desterritorialização: do "fim dos territórios" à multiterritorialidade. Rio de Janeiro: Bertrand Brasil, 2004.

Identidades territoriais. (In): CÔRREA, Roberto Lobato; ROSENDAHL, Zeny. Manifestações da cultura no espaço. Rio de Janeiro: UERJ, 1999.

COSTA, Wanderley Messias. Geografia política e geopolítica. São Paulo: Hucitec, 1992.

GALVÃO, Maria Rita Eliezer. Crônica do cinema paulistano. São Paulo: Ática, 1975.

OLIVEIRA, Lícia Mara Alves de. Salas de Cinema em São Paulo. Trabalho de Conclusão de Curso (Graduação em Arquitetura) - FAU, USP. São Paulo, 2003.

SANTINI, R. C. G. Dimensões do lazer e da recreação: questões espaciais e psicológicas. São Paulo: Angelotti, 1993.

SANTORO, Paula Freire. A relação da sala de cinema com o espaço urbano em São Paulo; do provinciano ao cosmopolita. Dissertação (Mestrado em Urbanismo) - FAU, USP. São Paulo, 2004.

SIMÕES, Inimá F. Salas de cinema em São Paulo. São Paulo: Secretaria Municipal de Cultura: PW, 1990.

STEFANI, Eduardo Baider. A territorialidade dos cinemas de arte e seus frequentadores na região da Avenida Paulista. Trabalho de Graduação Individual (Graduação em Geografia) FFLCH, USP. São Paulo, 2007.

TURNER, Graeme. Cinema como prática social. São Paulo: Summus, 1997.

Enviado para publicação em novembro de 2011.

Aceito para publicação em dezembro de 2011. 